\title{
Preparing your intensive care unit for the COVID-19 pandemic: practical considerations and strategies
}

\author{
Ken Junyang Goh ${ }^{1 *+} \mathbb{D}$, Jolin Wong ${ }^{2+}$, Jong-Chie Claudia Tien ${ }^{2}$, Shin Yi $\mathrm{Ng}^{2}$, Sewa Duu Wen ${ }^{1}$, \\ Ghee Chee Phua ${ }^{1}$ and Carrie Kah-Lai Leong ${ }^{1}$
}

\begin{abstract}
The coronavirus disease 2019 (COVID-19) has rapidly evolved into a worldwide pandemic. Preparing intensive care units (ICU) is an integral part of any pandemic response. In this review, we discuss the key principles and strategies for ICU preparedness. We also describe our initial outbreak measures and share some of the challenges faced. To achieve sustainable ICU services, we propose the need to 1) prepare and implement rapid identification and isolation protocols, and a surge in ICU bed capacity; (2) provide a sustainable workforce with a focus on infection control; (3) ensure adequate supplies to equip ICUs and protect healthcare workers; and (4) maintain quality clinical management, as well as effective communication.
\end{abstract}

Keywords: Coronavirus disease 2019, SARS-CoV-2, Critical care, Infection control, Pandemic preparedness

\section{Background}

Coronavirus disease 2019 (COVID-19) caused by severe acute respiratory syndrome coronavirus 2 (SARS-CoV-2) has rapidly developed into a worldwide pandemic $[1,2]$. Initial studies from China reported a high incidence of acute respiratory distress syndrome (ARDS) (17-29\%) and critical illness (23-32\%) among hospitalised patients [3-6]. Similar rates of critical illness (16\%) were also reported in Lombardy, Italy [7]. While these incidence rates are difficult to interpret and may be overestimated due to differences in availability of diagnostic testing, surveillance resources, and outpatient management of patients with mild illness, it appears that many patients who do develop critical illness do not survive. The reported 28-day ICU mortality rates are alarmingly high (62\%) [4], and greater than mortality rates seen with

\footnotetext{
* Correspondence: ken.goh.junyang@singhealth.com.sg

${ }^{\dagger}$ Ken Junyang Goh and Jolin Wong contributed equally to this work.

'Department of Respiratory and Critical Care Medicine, Singapore General Hospital, Outram Road, Singapore 169608, Singapore

Full list of author information is available at the end of the article
}

severe ARDS [8]. While the estimated case fatality rate of COVID-19 (3-4\%) [9] is lower compared to Middle East respiratory syndrome (MERS) (34\%) and severe acute respiratory syndrome (SARS) (11\%), deaths from COVID-19 has already far exceeded the combined deaths from MERS and SARS [10].

ICUs will be simultaneously challenged on multiple fronts. These include resource limitations, infection control, protection of healthcare workers (HCWs), and adaptation of services to a rapidly evolving pandemic situation. During the early phase of the outbreak in Wuhan, China, shortages in equipment meant that $75 \%$ of the deceased did not receive mechanical ventilation [11]. ICU resources in Lombardy, Italy, are also reported to be overwhelmed [7]. Clearly, the ability to maintain sustainable critical care services is a key consideration for all healthcare systems.

Singapore was among the first countries to experience an outbreak of COVID-19 [12], with approximately 10$15 \%$ of patients requiring invasive mechanical ventilation [13]. In this article, we aim to describe the critical care 
response in the largest academic tertiary medical centre in Singapore. The main targets to achieve are to (1) prepare and implement rapid identification and isolation protocols, and a surge in ICU bed capacity; (2) provide a sustainable workforce with a focus on infection control; (3) ensure adequate supplies to equip ICUs and protect HCWs; and (4) maintain quality clinical management, as well as effective communication. We review strategies employed with regard to ICU "SPACE", "STAFF", "SUPPLIES", and "STANDARDS" (Table 1) [14, 15].

\section{Key strategies at different phases of a pandemic}

When faced with sporadic cases or defined clusters in the community, maximising containment to reduce community impact and buy time for preparations is the key priority. Within healthcare institutions, this is achieved with rapid identification and isolation of suspect or confirmed COVID-19 cases, and strict infection control measures to minimise intra-hospital transmission and prevent incapacitation of essential services. A study from Wuhan, China, reported 41\% of COVID-19 cases attributable to hospital-related transmissions, with the majority (70\%) being HCWs [3]. In Italy, up to $20 \%$ of responding HCWs were also reported to be infected [16], emphasising the need for strict containment measures. If national and regional containment measures fail, healthcare systems are at risk of being rapidly overwhelmed [7]. In the event of sustained widespread community transmission, emphasis then shifts towards supporting essential hospital services, such as critical care and emergency care, to maximise mitigation whilst maintaining containment efforts. The planned response is a continuum and will vary based on the scale and severity of the pandemic [14].

\section{SPACE: critical care beyond the ICU} Designating an isolation ICU

Designation of an isolation ICU ward, geographically separated from other clinical areas, allows for concentration and segregation of equipment and staff, contributing to more effective containment. Isolation ICUs should ideally consist of negative pressure airborne infectious isolation rooms (AIIRs). AIIRs are kept at negative pressure relative to surroundings and ventilated with at least 6-12 air changes per hour (Fig. 1a), with any recycled air filtered before recirculation [17]. For hospitals without AIIRs, containment may also be maximised with a dedicated ICU and strict infection control measures. If single rooms are unavailable, cohorted patients should ideally be nursed at least $2 \mathrm{~m}$ apart with engineering controls (separation with physical barriers) [18].

\section{Rapid identification and isolation of suspected or confirmed cases}

Rapid identification and isolation of suspected COVID19 cases requires an efficient triaging protocol and access to rapid diagnostic testing. In our centre, all patients are screened at the emergency department, inpatient wards, and outpatient clinics. Based on screening questionnaires (travel and contact history), symptoms, and preliminary investigations (chest radiographs), patients are stratified into COVID-19 risk levels and admitted into open wards, cohort beds, single room beds, or negative pressure isolation rooms, respectively. With guidance from government authorities, our hospital's 'outbreak response command centre' constantly updates necessary changes to our COVID-19 risk stratification protocols, which are immediately disseminated to HCWs. Diagnostic testing is performed on specimens (pharyngeal swabs, or lower respiratory tract samples if applicable) for SARS-CoV-2 with real-time reverse transcriptase-polymerase chain reaction (RT-PCR) - we emphasise that healthcare systems need to ensure that there is adequate infrastructure and facilities to enable rapid testing.

As with other respiratory viruses, SARS-CoV-2 is believed to be most contagious when patients are symptomatic. However, unlike MERS and SARS [19], transmission of SARS-CoV-2 may occur even with mild or asymptomatic illness [20]. This complicates identification of cases and contact tracing. In Singapore, comprehensive and coordinated contact tracing is done at the hospital and national level to maximise containment efforts [21]. Our suspect case definition is currently based on a combination of travel and contact history, and presence of respiratory illness [22]. Patients who do not fulfil these criteria but have respiratory symptoms or chest imaging suggestive of a respiratory infection are cohorted to designated 'acute respiratory illness' wards for surveillance and segregation. Each healthcare system will need to constantly evolve their protocols and suspected case criteria to balance safety, yet optimise resource utilisation $[23,24]$.

\section{Maintaining ICU surge capacity}

In general, ICUs should be equipped to expand immediately by at least $20 \%$ above baseline capacity [14]. During a pandemic, however, significantly higher surge ICU capacity is needed and critically ill patients may need to receive care outside of a traditional ICU [14]. The planned response will depend on available resources, and trigger targets for activation of each phase of response should be defined early.

Alternative sites to care for critically ill patients must be identified early. In our centre, plans are made to allow for the immediate conversion of all isolation AIIRs 
Table 1 Summary of considerations and strategies to maintain ICU capacity and services

\begin{tabular}{lll}
\hline & Containment or alert phase* $^{*}$ & Pandemic or crisis phase* \\
\hline Scenario & $\begin{array}{l}\text { Limited community spread isolated to } \\
\text { individuals or clusters }\end{array}$ & Sustained widespread community transmission \\
Key strategy & Containment and preparedness & Mitigation and containment \\
SPACE & Designate an isolation ICU, with negative pressure AllR \\
& Rapid identification and isolation of suspected/known COVID-19 cases \\
& Ensure access to rapid diagnostic testing (e.g. laboratory facilities) \\
& Initiate planning for surge ICU bed capacity
\end{tabular}

Utilise normal pressure ICU beds or existing monitored beds (e.g. OT, PACU, high dependency, endoscopy suites, emergency department)

Alternative: cohort beds with physical barriers (e.g. curtains) in between patients

Ensure timely step-down of stable patients with deisolation protocol

Mass critical care: triaging protocol for patients with consideration for available resources, ethical principles, and public engagement

STAFF Staff segregation into 'frontline' teams

Implement strict infection prevention and control measures

Education of HCWs on infection control measures with just-in-time N95 fit testing

In situ, just-in-time simulation training with before-and-after multidisciplinary peer-review processes

Periodic re-training of HCW on infection control measures

Staff surveillance (e.g. temperature monitoring) and access to designated staff clinics

Ensure dissemination of timely and factual information and establish two-way communication

Provide helplines and psychological support, temporary staff quarters, gratitude messages from hospitals and public

Initiate ICU hands-on training for non-critical care nurses and ICU refresher courses for HCW using online materials and instructional videos

Minimise unnecessary procedures and transport

Increase manpower capacity by changing work structure (e.g. extra shifts or work hours) and restricting leave

Suspend elective procedures and non-essential services

Redeployment of HCW with critical care experience from other departments into ICUs

Consider reducing nurse- and doctor-to-patient ratios

Mass critical care: reassign non-intensive care HCW from other departments to support essential services, with ICU nurses providing a supervisory role

SUPPLIES Ensure adequate supply and stockpiles of PPE, essential consumables, medication, and equipment

Source for alternative supply channels for supplies and equipment; consider extended use of supplies/consumables where safe to do so and rationalise use of essential medications

Switch to single-use items (e.g. disposable bronchoscopes)

Segregate equipment (e.g. designated ultrasound machines)

Harmonise item purchase within hospital and clusters

Ensure adequate cleaning services and waste management capacity

Consider extended or limited re-use of N95 respirators

Consider alternatives to $\mathrm{N} 95$ respirators, e.g. PAPR

Rationalise the use of $\mathrm{N} 95$ respirators (e.g. risk stratify by activity type)

Obtain alternative sources of mechanical ventilators

Utilise stockpiled transport ventilators if available

Mass critical care: use alternative forms of respiratory support (e.g. NIV, HFNC) to replace invasive mechanical ventilation 
Table 1 Summary of considerations and strategies to maintain ICU capacity and services (Continued)

\begin{tabular}{l} 
Containment or alert phase* Pandemic or crisis phase* \\
\hline STANDARDS \\
Maintain clinical standards and principles of ARDS (e.g. lung protective ventilation, prone ventilation when appropriate) \\
Consider early intubation; avoid NIV in the absence of evidence-based indications \\
Adapt resuscitation and emergency procedural workflows to optimise patient safety and minimise risk of transmission \\
Identify ECMO referral centre, establish referral and transport workflows \\
Establish a hospital outbreak response command centre for effective communication and coordination \\
Inter- and intra-hospital teleconferencing to share experience and knowledge \\
Coordinate hospital ICU efforts with regional and national plans \\
Continue to engage patients' relatives \\
Utilise public relations and communications resources to build public trust
\end{tabular}

ICU intensive care unit, AIIR airborne infection isolation room, COVID-19 coronavirus disease 2019, OT operating theatre, PACU post-anaesthesia care unit, HCW healthcare worker, PPE personal protective equipment, PAPR powered air-purifying respirator, NIV non-invasive ventilation, HFNC high-flow nasal cannula therapy, $A R D S$ acute respiratory distress syndrome, ECMO extracorporeal membrane oxygenation

*The planned response should ideally be a phased or tiered response or a continuum-based response which evolves along with the impact of the pandemic

into ICU beds. Beyond this, patients will be cared for in existing ICU beds. We have also made comprehensive plans for the use of existing monitored beds (e.g. high dependency units, post-anaesthetic care units, operating suites, endoscopy suites) and cohorting of confirmed cases in designated areas. It is important that ICU bed planning should take into consideration the availability of oxygen ports, compressed air supply, clean water, and drainage systems [18]. Concurrent timely discharge to step-down care areas is critical and enables ICU resources to be used effectively. By this time, all elective surgeries and non-essential services need to be suspended so that resources can be quickly redirected.

At the extreme end of the surge continuum, 'emergency mass critical care practices' will have to be instituted which may come at a cost of suboptimal standards
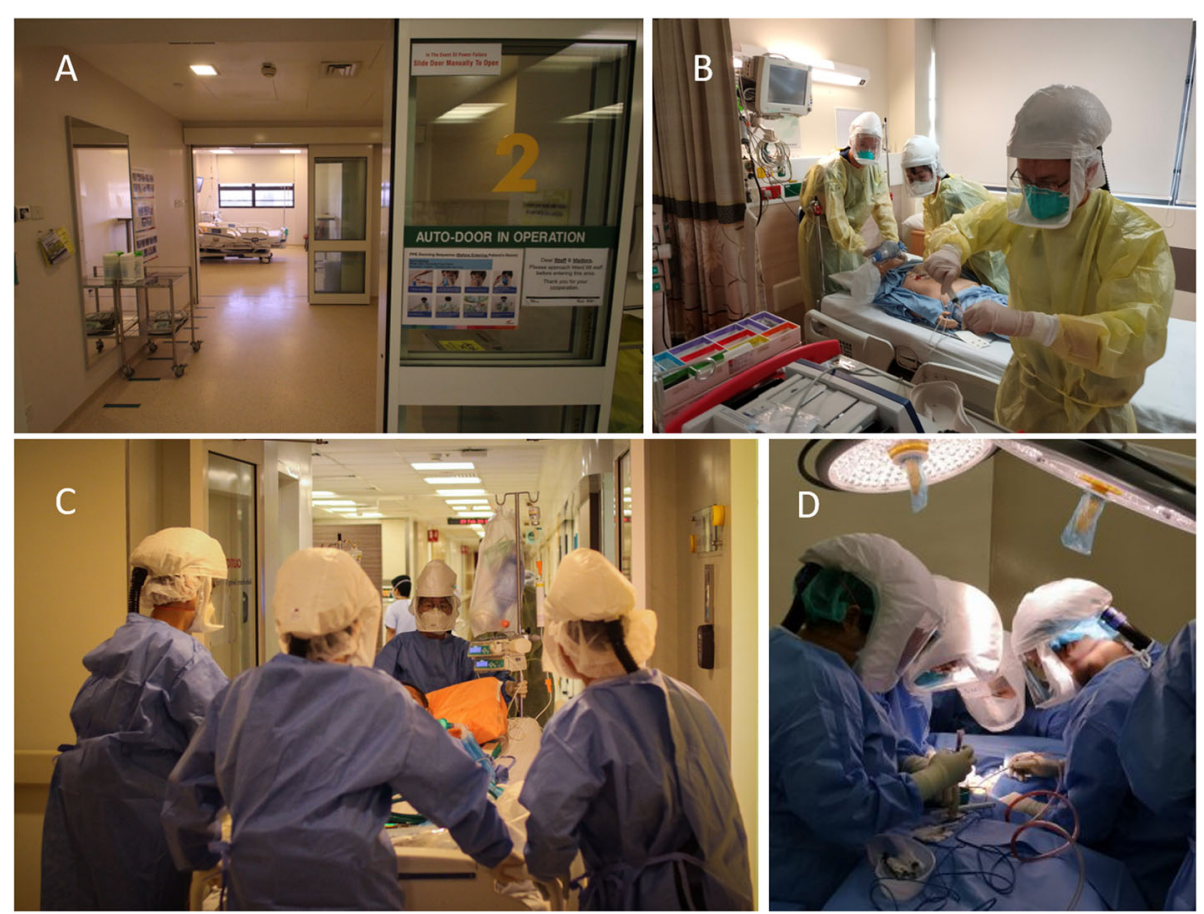

Fig. 1 Infection control and prevention. a Negative pressure airborne infection isolation rooms (AllRs) used for our isolation ICUs. b Cardiac arrest simulation training with disposable caps, gloves, and fluid-resistant gowns, eye protection along with respiratory protection using a fit-tested National Institute of Occupational Safety and Health (NIOSH) certified disposable N95 filtering facepiece respirator and powered air-purifying respirators (PAPRs). c Transport checklists and protocols (movement plans) were determined and rehearsed before actual implementation. $\mathbf{d}$ Operative procedures performed with PAPR in preparation for the COVID-19 pandemic 
of care [14, 24]. This may mean that high-flow nasal cannula (HFNC) therapy or non-invasive ventilation (NIV) is used to mitigate acute ventilator shortages, even though they do not constitute preferred management due to infection control concerns (aerosolisation of respiratory droplets). Triage of critically ill patients may become necessary to prioritise ICU resources, and ethical principles must be carefully considered to ensure just and equitable delivery of care for all patients [2527]. Triaging protocols should not disadvantage patients without COVID-19 who need ICU care. Healthcare systems must find a balance between 'saving the most lives' and prioritising care based on the likelihood of clinical benefit [28]. These criteria should ideally be objective, transparent, and publicly disclosed. Authorities should engage the community in this process so that public trust exists when it is most needed [25-27, 29].

\section{STAFF: maintaining service capabilities and protecting healthcare workers}

\section{Establish infection control measures}

Infection prevention and control is essential to protect both patients and HCWs [30]. Experience from SARS demonstrated the vulnerability of HCWs, and an uncontrolled in-hospital outbreak can devastate an entire hospital's services within days [31, 32]. Critical care HCWs are at high risk considering the higher exposure dose from aerosol-generating procedures and longer periods of patient contact. In addition, the reproductive number for SARS-CoV-2 (between 2 and 2.5) and therefore transmissibility is significantly higher than seasonal influenza [33]. As with other respiratory viruses, it is likely that SARS-CoV-2 spreads predominantly through contact (direct or indirect) and droplet transmission. Though faecal shedding of the virus has been demonstrated, faecal-oral transmission remains unproven [34]. Strict adherence to droplet and contact precautions including hand hygiene, eye protection, and safe donning and doffing of personal protective equipment (PPE) will be the main defences against transmission. A summary of recommended infection control measures is presented in Table 2.

Airborne transmission with respiratory viruses remains controversial [37], although it is likely that any airborne transmission with COVID-19 will be opportunistic in nature [38]. Studies on SARS-CoV and MERS-CoV have highlighted the possibility of airborne transmission with aerosol-generating procedures such as intubation [17], manual ventilation [39], NIV, and tracheotomy [40]. Until more is known about COVID-19 transmission, we recommend airborne precautions during aerosol-generating procedures in all patients (COVID-19 or otherwise) [17]. Disposable caps, gloves and fluid-resistant gowns, eye protection, and respiratory protection using a fit-tested National Institute of Occupational Safety and Health (NIOSH) certified disposable N95 particulate filtering facepiece respirator are used in our centre [17]. Powered air-purifying respirators (PAPRs) are alternatives, but careful doffing and disinfection is necessary to prevent self-contamination [41]. HCWs must doff and dispose of PPE safely within designated areas, with equipment and environmental decontamination enforced.

Other potential aerosol-generating procedures (e.g. airway suctioning, nebuliser treatment, bronchoscopy, chest physiotherapy, and HFNC) have not been conclusively established to increase the risk of viral transmission [40]. Nevertheless, we discourage nebulised therapy (metered dose inhalers with or without a spacer are used instead) and use closed in-line suction for tracheal aspiration in our centre. With no clear mortality benefit with HFNC therapy in respiratory failure, our preferred management is conventional oxygen therapy and early intubation [42]. NIV is considered only with evidence-based indications, in view of high failure rates and poor outcomes seen with MERS-CoV [43]. However, we do recognise that in the event of severe ventilator shortages, these modes of respiratory support may have to be utilised-ideally with strict infection control measures. In our institution, mechanical high-efficiency particulate air (HEPA) or pleated hydrophobic filters are fitted to mechanical ventilators at expiratory ports, as well as NIV mask and bag-valve-mask interfaces (Fig. 2). It should be noted that airway resistance and circuit dead space may be increased as a result [44-47].

\section{Education and re-training}

Education is important for effective infection control, upskilling HCWs, and identifying logistical and technical challenges with routine or ICU care. HCWs should be taught to inspect, disinfect, and dispose of PPE safely, and periodic refresher re-training is required to ensure staff readiness and proficiency. In our centre, an online critical care refresher course was organised for nonintensivist physicians, with voice-annotated lectures on ICU management and instructional videos on ventilator set-up and troubleshooting.

From our experience, simulation training has been invaluable in ensuring the preparedness of HCWs $[48,49]$. We instituted 'just-in-time' inter-professional and in situ simulations. These included resuscitation and rapid response team training, extracorporeal membrane oxygenation (ECMO), transport of critically ill patients, and procedures like tracheostomy (Fig. 1), performed with full airborne precautions and PAPR. These helped to recognise and address unexpected problems, which led to downstream rectification. For example, cardiac arrest simulations revealed several violations of infection control during cardiopulmonary resuscitation, and challenges such as 
Table 2 Summary of infection prevention and control measures

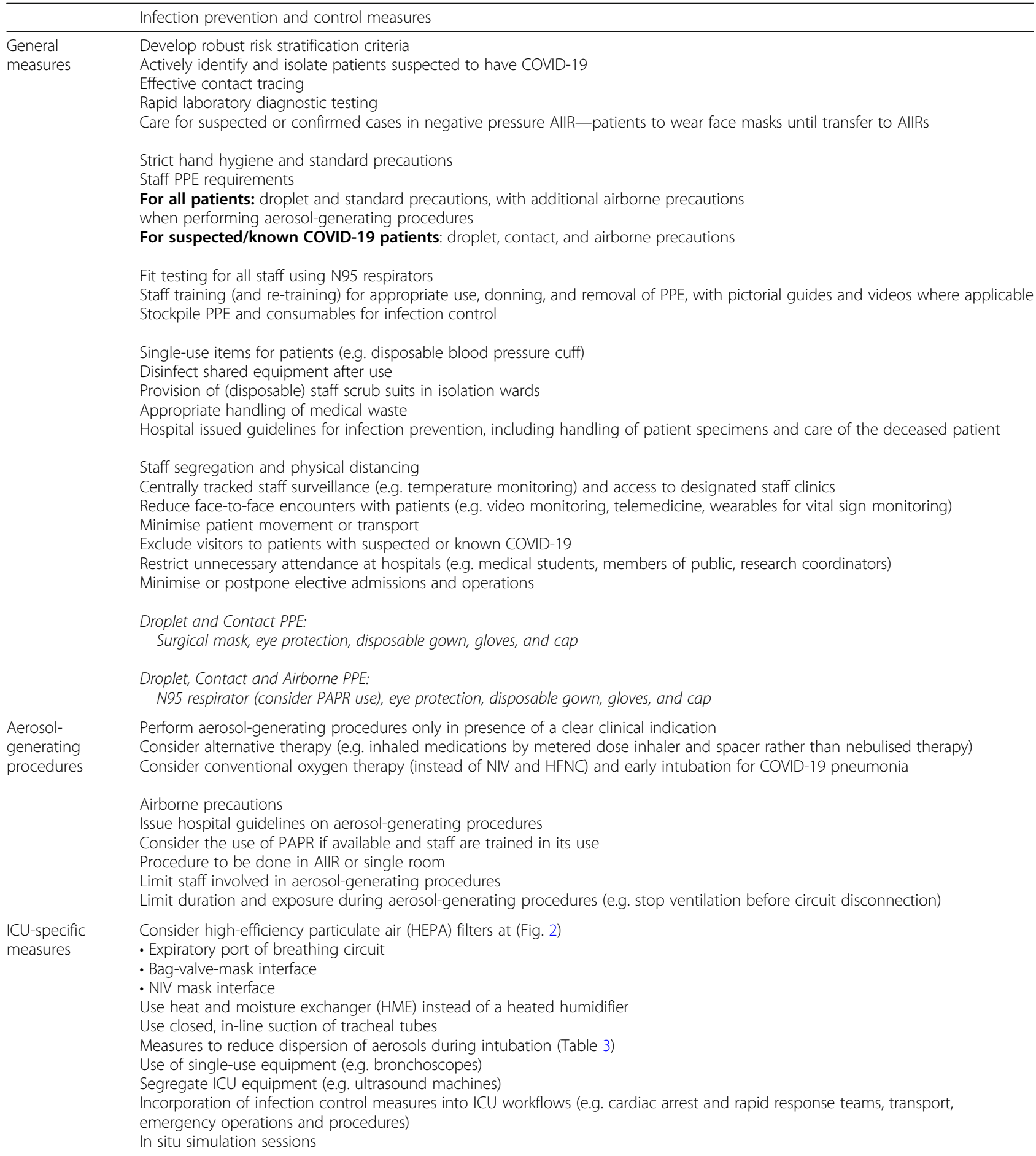

COVID-19 coronavirus disease 2019, AIIR airborne infection isolation room, PPE personal protective equipment, PAPR powered air-purifying respirator, NIV noninvasive ventilation, HFNC high-flow nasal cannula therapy, ICU intensive care unit

difficulties in auscultating for breath sounds while using PAPR. This triggered the recommendation for infection control re-training and posters for PPE doffing to be placed in all isolation wards. End tidal carbon dioxide monitoring was also used to confirm endotracheal tube placement for all intubations. Transport with full-feature ICU ventilators also revealed problems with limited internal battery lifespan, and physical bulk even with the largest available cargo lifts. Protocol changes to use transport ventilators fitted with HEPA filters were then made. 


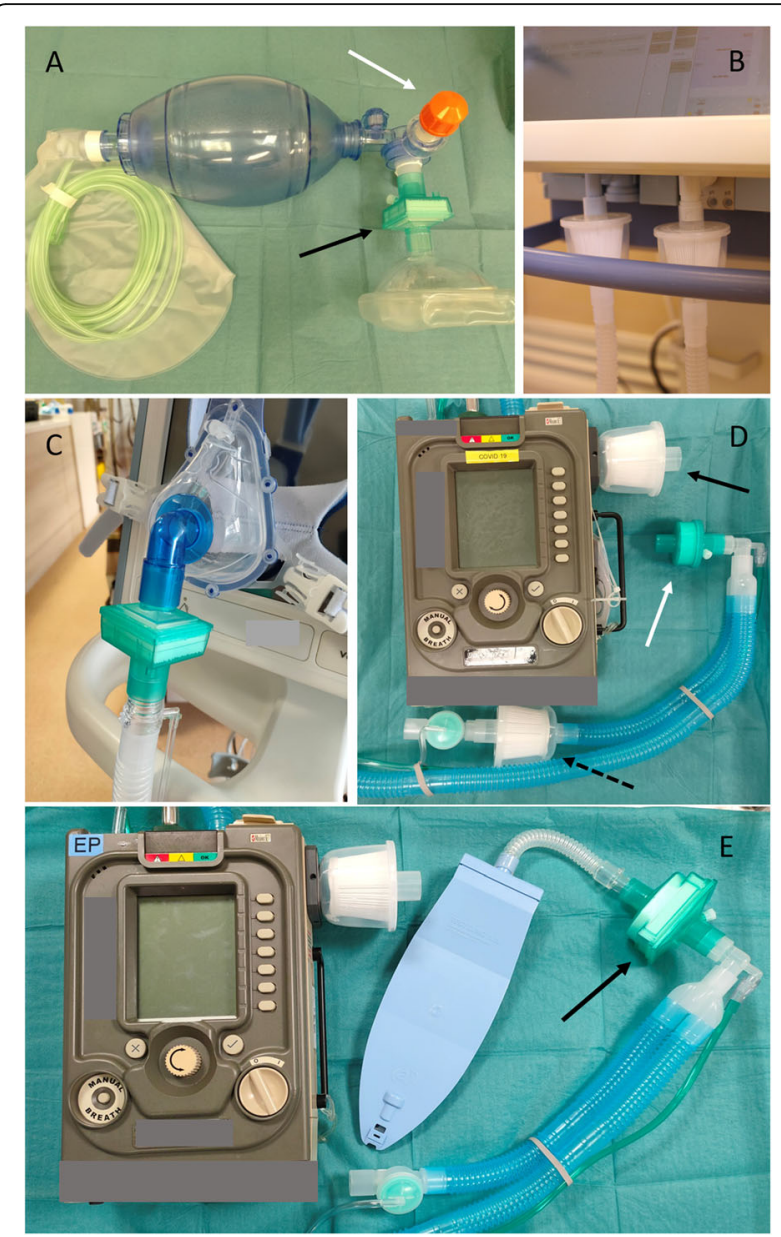

Fig. 2 Breathing circuit filters. Connections should be tightly fitted to avoid disconnections during movement. Dead space and circuit resistance will increase with the use of filters. a Hydrophobic mechanical filter at the bag-valve-mask interface (black arrow) to reduce dispersion of respiratory droplets during manual ventilation with a positive end expiratory pressure (PEEP) valve (white arrow) to optimise pre-oxygenation. b HEPA (high-efficiency particulate air) filters used on the inspiratory and expiratory ports of mechanical ventilators. c Hydrophobic mechanical filter used before the external expiratory port on a single-limb non-invasive ventilator circuit. $\mathbf{d}$ HEPA filters used at the air inlet (solid black arrow) and before the exhalation valve (dashed black arrow) ports of a single-limb transport ventilator circuit. A standard HME (heat and moisture exchanger) (white arrow) is attached at the Y-piece of the breathing circuit. e An alternative combination is the use of HEPA filter at the air inlet and a hydrophobic mechanical HME filter (HMEF) (black arrow) at the Y-piece, nearest to the patient

Multidisciplinary peer-review processes were also held after each procedure with COVID-19 patients, where HCWs and relevant stakeholders were debriefed and process improvements discussed.

\section{Segregation and surveillance}

HCWs should be segregated to reduce the risk of crosstransmission. This allows for service continuity, should a team be quarantined. In our centre, HCWs caring for COVID-19 patients are also not permitted to care for other patients and are relieved of outpatient responsibilities. In our ICUs, we allocated 'frontline' teams of doctors, nurses, and allied health staff, with defined geographical coverage for each team. Teleconferences replaced face-to-face meetings. HCWs were instructed to record temperature surveillance readings twice a day and submit these to an online platform that is centrally tracked to facilitate early detection of any intra-hospital outbreak. HCWs with fever or respiratory symptoms are also required to report to designated staff clinics, with COVID-19 testing and/or stay home instructions implemented as required.

\section{Maintaining manpower capability}

With the need for strict infection control measures, routine procedures in the ICU will require additional manpower and time [49]. In our isolation ICU, the nurse-to-patient ratio was increased to approximately $1.5: 1$, with critical care nurses focused on providing care and supported by noncritical care nurses who assisted in preparing drugs and equipment outside the AIIRs. Infection control specialty nurses assisted ICU staff in appropriate donning and doffing of PPE. In addition, doctors and nurses with previous critical care experience were also reassigned from other departments to extend frontline coverage to 24 hours a day.

In the event of widespread community transmission, critical care manpower capabilities will be easily overwhelmed. It will then be necessary to draw manpower from various departments and divisions in the hospital. In our centre, critical care crash courses are being held continuously for non-critical care nurses with online learning materials, instructional videos, and hands-on practicums supervised by critical care nurses in nonisolation ICUs. Manpower is also being drawn from nurses with critical care experience, recently retired ICU nurses, and private hospital nurses. Nurses from various subspecialty centres within the extended hospital campus can augment non-critical care nursing roles, such as infection control [50]. Critical care intensivist- or nurseto-patient ratios should be re-evaluated frequently, guided by clinical demands, provider experience, and available support by ancillary staff [50]. With critical shortages in manpower, intensivists and ICU nurses may have to take up a supervisory role, with non-critical care $\mathrm{HCWs}$ providing direct care to patients.

High workload and anxiety over disease transmission can result in significant physical and mental fatigue [51]. To mitigate this, we established open communication channels and rapid dissemination of information to keep staff informed of new developments. Psychological support resources and a helpline are also made available. Sections of a community hospital building were repurposed as optional temporary staff quarters. Despite best 
intentions, 'presenteeism', the act of coming to work whilst ill, potentially increases the risk of intra-hospital transmission [52]. Policies must ensure that HCWs seek early medical attention and stay home when ill.

\section{SUPPLIES: equipping ICUs}

In a disease outbreak, requirements for equipment and supplies including PPE increase tremendously. Allied health and support services, including pharmacy, laboratory, and respiratory therapy services, must be engaged in advance to identify the highest priority supplies and medications required. To avoid supply chain vulnerabilities, alternative agents and supply channels should be identified [53]. Equipment, supplies, and pharmaceutical stockpiles should be harmonised as far as possible within the hospital and between regional hospitals [50]. Singleuse items (e.g. disposable laryngoscope blades and bronchoscopes) may be preferable. For reusable items, it is important to ensure adequate capacity for prompt disinfection and sterilisation.

Careful use of PPEs can help to conserve supplies required for infection control. Extended use and limited re-use of N95 respirators may be implemented with appropriate precautions (e.g. strict hand hygiene, reusable face shield over an N95 respirator) [54]. Other options include alternative respirators (e.g. elastomeric respirators, PAPRs) or prioritising use of respirators by activity type (e.g. aerosol-generating procedures) while masking symptomatic patients [55].

Our centre has additional full-feature invasive mechanical ventilators and transport ventilators ready for deployment to allow immediate expansion of ICU services. If greater capacity is required, ventilators from operating theatres and other monitored units and transport ventilators from national stockpiles are available. Apart from an expected surge in demand for drugs such as sedatives, analgesic agents, and neuromuscular blockade agents, specific drugs will also be required during a pandemic. The route of drug delivery must be considered. For example, lopinavir/ritonavir, usually given as a tablet, may need to be administered in a syrup formulation for critically ill patients. Crushing the tablet form may result in poorer efficacy due to interactions between the two active components of the drug [56].

Finally, significant amounts of biohazard waste will be generated while caring for critically ill patients. Adequate waste management capacity is necessary to upkeep a safe environment for HCWs and patients [57]. Environmental cleaning appears to be effective against SARS-CoV-2 [58]; however, terminal cleaning will need to keep pace with clinical services to maximise bed capacity.

\section{STANDARDS: ensuring quality clinical care} Management of critical illness from COVID-19

We still have a poor understanding of clinical features of critical illness in COVID-19. Based on the current evidence, the spectrum of disease severity appears to vary significantly from asymptomatic or mild symptoms to critical illness with a high mortality rate [4]. Critical illness appears to develop most commonly between 1 and 2 weeks after symptom onset $[3,5]$. Ground glass opacities are typical findings on chest imaging, with basal consolidation seen in some patients $[59,60]$. However, chest radiograph or computed tomography (CT) imaging can be normal, even in patients who subsequently develop critical illness [61]. In addition, patients can develop rapid deterioration and progression to ARDS [62]. Risk factors for critical illness include advanced age ( $\geq 60$ years) and pre-existing comorbidities (cardiovascular disease, cerebrovascular disease, chronic pulmonary disease) [3, 61, 63]. Biochemical 'markers' including significant lymphopenia, elevated lactate dehydrogenase or d-dimer, and neutrophilia are associated with more severe disease $[3,5,63]$. Nosocomial or secondary infections appear to be common (14-31\%) in critically ill patients $[4,5]$. It remains unclear if COVID-19 can result in fulminant myocarditis [63].

Until more evidence emerges, management of COVID19-induced ARDS should not differ from conventional ARDS management $[64,65]$. These include lung protective ventilation, a fluid conservative strategy when appropriate, and early initiation of prone ventilation for severe ARDS [66-68]. When appropriate, early neuromuscular blockade may be considered for moderate-severe ARDS [69]. Referral to an ECMO centre, for refractory hypoxemia or if lung protective ventilation cannot be applied, remains an option. Corticosteroids should not be routinely administered [70], with concerns of delayed viral clearance or worse patient outcomes extrapolated from studies with SARS and MERS-CoV [71, 72]. Whilst there is no proven anti-viral therapy for COVID-19 to date, ongoing trials include the use of remdesivir, which has shown some promise in in vitro studies [73]. More research is urgently needed to fill knowledge gaps in terms of disease clinical course, prognostic markers, treatment options, and transmission dynamics, which will be critical for ICU management and resource planning.

\section{Intubation and airway codes}

The principles of airway management are, firstly, to optimise patient safety and, secondly, to minimise the risk of transmission to HCWs. Table 3 summarises the recommendations for intubation of the COVID-19 patient. Physicians should have a lower threshold to call for help in a predicted difficult intubation. This allows the airway code team additional preparation time (donning of PPE) and minimises multiple attempts at intubation and 
Table 3 Recommendations for intubation and transport of a suspected/known COVID-19 patient

\begin{tabular}{|c|c|c|}
\hline & Optimise patient safety & Infection prevention and control \\
\hline Preparation & $\begin{array}{l}\text { Early identification of patients requiring intubation [35] } \\
\text { Formulate airway plans A, B, C, D } \\
\text { Don PPE with airborne precautions } \\
\text { Prepare all equipment for intubation } \\
\text { - Airway } \\
\text { - Breathing devices, e.g. bag-valve-mask device } \\
\text { - Breathing circuit }\end{array}$ & $\begin{array}{l}\text { *Intubate within an AlIR }[17,36] \\
\text { PPE and airborne precautions for all staff }[17,36] \\
\text { HEPA filter to reduce circuit and environmental contamination } \\
\text { (Fig. 2a) }\end{array}$ \\
\hline Intubation & $\begin{array}{l}\text { Preoxygenation for } 5 \text { min, with 'head-up' positioning when } \\
\text { possible } \\
\text { Consider PEEP valve with bag-valve-mask pre-oxygenation } \\
\text { Consider nasal cannula ( } 15 \mathrm{~L} / \mathrm{min} \text { ) for apnoeic oxygenation } \\
\text { Intubation by the most experienced operator } \\
\text { Use video laryngoscope to optimise view through PAPR or } \\
\text { goggles }\end{array}$ & $\begin{array}{l}\text { Ensure good mask seal } \\
\text { Avoid HFNC for pre-oxygenation } \\
\text { Rapid sequence induction-minimise need for face mask } \\
\text { ventilation [35] } \\
\text { Small tidal volumes if ventilation unavoidable [35] } \\
\text { Ensure full paralysis to reduce coughing [35] }\end{array}$ \\
\hline Post-intubation & $\begin{array}{l}\text { Confirm tracheal tube position with capnography (difficult } \\
\text { auscultation with hooded PAPR) }\end{array}$ & $\begin{array}{l}\text { Positive pressure ventilation to be initiated only after cuff is } \\
\text { inflated } \\
\text { Sedation and paralysis to reduce coughing }\end{array}$ \\
\hline $\begin{array}{l}\text { Transport of the } \\
\text { intubated patient }\end{array}$ & $\begin{array}{l}\text { Consider if transport is necessary } \\
\text { Sedation and paralysis to reduce risk of coughing or } \\
\text { inadvertent self extubation }\end{array}$ & $\begin{array}{l}\text { HEPA filters for circuit and transport ventilator (Fig. 2) } \\
\text { Place ventilators on standby mode and clamp tracheal tube for } \\
\text { the period of disconnection [36] } \\
\text { Adhere to a designated route with minimal contamination and } \\
\text { exposure to other clinical areas }\end{array}$ \\
\hline
\end{tabular}

COVID-19 coronavirus disease 2019, PPE personal protective equipment, PEEP positive end expiratory pressure, PAPR powered air-purifying respirator, AllR airborne infection isolation room, HFNC high-flow nasal cannula, HEPA high-efficiency particulate air

*Intubation should ideally be performed in an AIIR for suspected or known COVID-19 patients

manual ventilation. In our centre, dedicated airway kits were placed in isolation wards and in the emergency department for use on suspect and confirmed COVID-19 cases. Additional items such as N95 respirator masks, goggles (eye protection), and endotracheal tube (ETT) clamps, to limit aerosolisation following intubation, were added to the difficult airway equipment.

\section{Intensive care outreach}

All cardiac arrests in the hospital are managed with full PPE in the first instance [74]. A designated cardiac arrest team was assigned for the isolation wards in our hospital, segregating them from other geographically based teams. The remaining cardiac arrest teams were restructured to exclude contribution from the emergency medicine department, allowing for further segregation of manpower for emergency medicine services. Rapid response and outreach services should also be streamlined to reduce staff movement throughout the hospital. Should ICU resources be overwhelmed, these services may have to cease or be re-delegated with supervision from critical care teams.

\section{Transport of critically ill patients}

Table 3 lists recommendations for transport of intubated COVID-19 patients. A transport ventilator is used for our transports (Fig. 2). In the event of ventilator shortages, a full-feature ICU ventilator may be used instead; advantages include reduced circuit disconnections and the ability to deliver advanced modes of ventilation. However, additional oxygen tanks will have to be prepared as ICU ventilators are not able to utilise atmospheric air. It is important to ensure that battery life (external and/or internal batteries) is sufficient to last the entire duration of transport, procedure, or imaging.

\section{Emergency procedural workflows}

Workflows and service continuity for isolated patients who require emergency operations or interventional procedures should be determined. Dedicated operating theatres, radiology, and interventional suites, along with respective subspecialty teams, were designated in our institution $[75,76]$.

\section{Effective communication and coordination}

Effective communication is essential in a pandemic response. Information should be disseminated to all HCWs in a timely fashion, and two-way communication should be established. In our centre, information and protocol updates are disseminated to all HCWs daily by email and hospital intranet. In addition, ICUs will need to work closely with nursing services, infection control, supplies/engineering/cleaning services and other departments to harmonise efforts for a coordinated response. In our institution, an 'outbreak response command centre' involving key appointment holders discusses anticipated challenges and reviews protocols regularly. In 
Singapore, several ICU-led inter-hospital video conferences have also been organised to share knowledge. Finally, good coordination between local or regional hospitals, guided by government or national organisations, is a key component of the pandemic response with effective resource allocation [77].

\section{Family engagement}

Family engagement is important as visitors are largely excluded from isolation wards [78]. Effective communication is necessary to address concerns and manage expectations, or to help determine goals of care in the critically ill. Public relations departments and social workers should be involved to facilitate communication with family members or the public media, to minimise misunderstanding and build trust and confidence in the healthcare system [79].

\section{Conclusion}

The COVID-19 pandemic will place extraordinary and sustained demands on critical care services. Critical care providers must take the lead to initiate planning and rapidly implement measures to ensure that healthcare services are maintained. It is equally important to maintain critical care services for non-COVID-19 patients, protect HCWs, and consider the ethical and social implications of triaging during a crisis.

\section{Abbreviations}

COVID-19: Coronavirus disease 2019; SARS-CoV-2: Severe acute respiratory syndrome coronavirus 2; ARDS: Acute respiratory distress syndrome; MERSCoV: Middle East respiratory syndrome; SARS: Severe acute respiratory syndrome; ICU: Intensive care unit; HCW: Healthcare worker; AllR: Airborne infectious isolation room; RT-PCR: Real-time reverse transcriptase-polymerase chain reaction; HFNC: High-flow nasal cannula therapy; NIV: Non-invasive ventilation; PPE: Personal protective equipment; NIOSH: National Institute of Occupational Safety and Health; PAPR: Powered air-purifying respirator; HEPA: High-efficiency particulate air; ECMO: Extracorporeal membrane oxygenation; CT: Computed tomography

\section{Acknowledgements \\ We acknowledge all healthcare workers in our intensive care units, for your courage, fortitude, and dedication during this difficult period. We would like to acknowledge Ms. Patricia Yueh Li Yong, Constance Wei Shan Teo and Dr. Hui Zhong Chai for their contributions in planning and coordinating our intensive care unit response.}

\section{Authors' contributions}

All authors were major contributors in writing the manuscript and approved the final manuscript.

\section{Funding}

Not applicable

\section{Availability of data and materials \\ Not applicable}

Ethics approval and consent to participate

Not applicable

\section{Consent for publication}

Not applicable

\section{Competing interests}

The authors have no conflict of interests to declare.

\section{Author details}

'Department of Respiratory and Critical Care Medicine, Singapore General Hospital, Outram Road, Singapore 169608, Singapore. ${ }^{2}$ Division of

Anaesthesiology, Singapore General Hospital, Singapore, Singapore.

Received: 18 March 2020 Accepted: 22 April 2020

Published online: 11 May 2020

\section{References}

1. Novel Coronavirus (2019-nCoV) situation reports. Available: https://www. who.int/emergencies/diseases/novel-coronavirus-2019/situation-reports/. [cited 12 Mar 2020].

2. WHO Director-General's opening remarks at the media briefing on COVID19 - 11 March 2020. Available: https://www.who.int/dg/speeches/detail/ who-director-general-s-opening-remarks-at-the-media-briefing-on-covid-1 9\%2D\%2D-11-march-2020. [cited 12 Mar 2020].

3. Wang D, Hu B, Hu C, Zhu F, Liu X, Zhang J, et al. Clinical characteristics of 138 hospitalized patients with 2019 novel coronavirus-infected pneumonia in Wuhan, China. JAMA. 2020. https://doi.org/10.1001/jama.2020.1585.

4. Yang $X, Y u$ Y, Xu J, Shu H, J 'an X, Liu H, et al. Clinical course and outcomes of critically ill patients with SARS-CoV-2 pneumonia in Wuhan, China: a single-centered, retrospective, observational study. Lancet Respir Med. 2020. https://doi.org/10.1016/\$2213-2600(20)30079-5.

5. Huang C, Wang Y, Li X, Ren L, Zhao J, Hu Y, et al. Clinical features of patients infected with 2019 novel coronavirus in Wuhan, China. Lancet. 2020. https://doi.org/10.1016/s0140-6736(20)30183-5.

6. Chen N, Zhou M, Dong X, Qu J, Gong F, Han Y, et al. Epidemiological and clinical characteristics of 99 cases of 2019 novel coronavirus pneumonia in Wuhan, China: a descriptive study. Lancet. 2020;395:507-13.

7. Grasselli G, Pesenti A, Cecconi M. Critical care utilization for the COVID-19 outbreak in Lombardy, Italy: early experience and forecast during an emergency response. JAMA. 2020. https://doi.org/10.1001/jama.2020.4031.

8. Bellani G, Laffey JG, Pham T, Fan E, Brochard L, Esteban A, et al. Epidemiology, patterns of care, and mortality for patients with acute respiratory distress syndrome in intensive care units in 50 countries. JAMA. 2016;315:788-800

9. Novel Coronavirus (2019-nCoV) situation reports. Available: https:/uww.who.int/ emergencies/diseases/novel-coronavirus-2019/situation-reports. [cited 15 Mar 2020].

10. Park M, Thwaites RS, Openshaw PJM. COVID-19: lessons from SARS and MERS. Eur J Immunol. 2020;50:308-11. https://onlinelibrary.wiley.com/doi/ abs/10.1002/eji.202070035.

11. Xie J, Tong Z, Guan X, Du B, Qiu H, Slutsky AS. Critical care crisis and some recommendations during the COVID-19 epidemic in China. Intensive Care Med. 2020. https://doi.org/10.1007/s00134-020-05979-7.

12. Singapore confirms first case of Wuhan virus. In: CNA. Available: https:// www.channelnewsasia.com/news/singapore/wuhan-virus-pneumoniasingapore-confirms-first-case-12312860. [cited 25 Feb 2020].

13. $\mathrm{MOH}$ | Updates on COVID-19 (Coronavirus Disease 2019) Local Situation. Available: https://www.moh.gov.sg/covid-19. [cited 12 Mar 2020].

14. Hick JL, Einav S, Hanfling D, Kissoon N, Dichter JR, Devereaux AV, et al. Surge capacity principles. Chest. 2014:e1S-e16S. https://doi.org/10.1378/chest.14-0733.

15. Maves RC, Jamros CM, Smith AG. Intensive care unit preparedness during pandemics and other biological threats. Crit Care Clin. 2019:609-18. https:// doi.org/10.1016/j.ccc.2019.06.001.

16. The Lancet. COVID-19: protecting health-care workers. Lancet. 2020;395:922.

17. CDC. 2019 novel coronavirus (2019-nCoV). In: Centers for Disease Control and Prevention; 2020. Available: https://www.cdc.gov/coronavirus/2019nCoV/hcp/infection-control.html. [cited 20 Feb 2020].

18. How are suspect cases handled? Available: https://www.gov.sg/article/howare-suspect-cases-handled. [cited 15 Mar 2020].

19. Cheng VCC, Chan JFW, KKW T, Yuen KY. Clinical management and infection control of SARS: lessons learned. Antivir Res. 2013;100:407-19.

20. Hu Z, Song C, Xu C, Jin G, Chen Y, Xu X, et al. Clinical characteristics of 24 asymptomatic infections with COVID-19 screened among close contacts in Nanjing, China. Sci China Life Sci. 2020. https://doi.org/10.1007/s11427-020-1661-4.

21. Coronavirus: how contact tracers track down the people at risk of infection. In: The straits times. 2020. Available: https:/www.straitstimes.com/singapore/health/howcontact-tracers-track-down-the-people-at-risk-of-infection. [cited 15 Mar 2020]. 
22. $\mathrm{MOH}$ | News. Available: https://www.moh.gov.sg/hpp/all-healthcareprofessionals/news/NewsArticleDetails/list-of-areas-requiring-heightenedvigilance-included-in-the-suspect-case-definition-for-covid-19-(updated-on9-mar-2020). [cited 15 Mar 2020].

23. Christian MD, Devereaux AV, Dichter JR, Rubinson L, Kissoon N. Introduction and executive summary: care of the critically ill and injured during pandemics and disasters: CHEST consensus statement. Chest. 2014;146:8S-34S.

24. Rubinson L, Nuzzo JB, Talmor DS, O'Toole T, Kramer BR, Inglesby TV. Augmentation of hospital critical care capacity after bioterrorist attacks or epidemics: recommendations of the Working Group on Emergency Mass Critical Care. Crit Care Med. 2005;33:2393-403.

25. Kain T, Fowler R. Preparing intensive care for the next pandemic influenza. Crit Care. 2019:23:337.

26. Biddison LD, Berkowitz KA, Courtney B, De Jong CMJ, Devereaux AV, Kissoon $\mathrm{N}$, et al. Ethical considerations: care of the critically ill and injured during pandemics and disasters: CHEST consensus statement. Chest. 2014; 146:e145S-55S.

27. Thompson AK, Faith K, Gibson JL, Upshur REG. Pandemic influenza preparedness: an ethical framework to guide decision-making. BMC Med Ethics. 2006;7:12

28. Emanuel EJ, Persad G, Upshur R, Thome B, Parker M, Glickman A, et al. Fair allocation of scarce medical resources in the time of Covid-19. N Engl J Med. 2020. https://doi.org/10.1056/NEJMsb2005114.

29. Covid-19: how to triage effectively in a pandemic - The BMJ. In: The BMJ. 9 Mar 2020. Available: https://blogs.bmj.com/bmj/2020/03/09/covid-19-triagein-a-pandemic-is-even-thornier-than-you-might-think/. [cited 12 Mar 2020].

30. Joynt Oi Man G. Transmission of SARS to healthcare workers. Intensive Care Med. 2006;32:564-9.

31. Booth CM, Stewart TE. Severe acute respiratory syndrome and critical care medicine: the Toronto experience. Crit Care Med. 2005;33:S53-60.

32. Chowell G, Abdirizak F, Lee S, Lee J, Jung E, Nishiura H, et al. Transmission characteristics of MERS and SARS in the healthcare setting: a comparative study. BMC Med. 2015;13:210.

33. Li Q, Guan X, Wu P, Wang X, Zhou L, Tong Y, et al. Early transmission dynamics in Wuhan, China, of novel coronavirus-infected pneumonia. N Engl J Med. 2020. https://doi.org/10.1056/NEJMoa2001316.

34. Yeo C, Kaushal S, Yeo D. Enteric involvement of coronaviruses: is faecal-oral transmission of SARS-CoV-2 possible? Lancet Gastroenterol Hepatol. 2020. https://doi.org/10.1016/S2468-1253(20)30048-0.

35. Kamming D, Gardam M, Chung F. Anaesthesia and SARS. Br J Anaesth. 2003; 90:715-8.

36. Yam LYC, Chen RC, Zhong NS. SARS: ventilatory and intensive care. Respirology. 2003;8(Suppl):S31-5.

37. Kutter JS, Spronken MI, Fraaij PL, RAM F, Herfst S. Transmission routes of respiratory viruses among humans. Curr Opin Virol. 2018:142-51. https://doi. org/10.1016/j.coviro.2018.01.001.

38. Lei H, Li Y, Xiao S, Lin C-H, Norris SL, Wei D, et al. Routes of transmission of influenza A H1N1, SARS CoV, and norovirus in air cabin: comparative analyses. Indoor Air. 2018;28:394-403.

39. Raboud J, Shigayeva A, McGeer A, Bontovics E, Chapman M, Gravel D, et al. Risk factors for SARS transmission from patients requiring intubation: a multicentre investigation in Toronto, Canada. PLoS One. 2010;5:e10717.

40. Tran K, Cimon K, Severn M, Pessoa-Silva CL, Conly J. Aerosol generating procedures and risk of transmission of acute respiratory infections to healthcare workers: a systematic review. PLoS One. 2012;7:e35797.

41. Tompkins BM, Kerchberger JP. Special article: personal protective equipment for care of pandemic influenza patients: a training workshop for the powered air purifying respirator. Anesth Analg. 2010;111:933-45.

42. Monro-Somerville T, Sim M, Ruddy J, Vilas M, Gillies MA. The effect of highflow nasal cannula oxygen therapy on mortality and intubation rate in acute respiratory failure: a systematic review and meta-analysis. Crit Care Med. 2017:45:e449-56

43. Arabi YM, Arifi AA, Balkhy HH, Najm H, Aldawood AS, Ghabashi A, et al. Clinical course and outcomes of critically ill patients with Middle East respiratory syndrome coronavirus infection. Ann Intern Med. 2014;160:389-97.

44. Wilkes AR. Heat and moisture exchangers and breathing system filters: their use in anaesthesia and intensive care. Part 1 - history, principles and efficiency. Anaesthesia. 2011;66:31-9.

45. 1Wilkes AR. Heat and moisture exchangers and breathing system filters: their use in anaesthesia and intensive care. Part 2 - practical use, including problems, and their use with paediatric patients. Anaesthesia. 2011;66:40-51.
46. Heuer JF, Crozier TA, Howard G, Quintel M. Can breathing circuit filters help prevent the spread of influenza $\mathrm{A}(\mathrm{H} 1 \mathrm{~N} 1)$ virus from intubated patients? GMS Hyg Infect Control. 2013;8:Doc09.

47. Wilkes AR, Benbough JE, Speight SE, Harmer M. The bacterial and viral filtration performance of breathing system filters. Anaesthesia. 2000;55:45865.

48. Wallace D, Gillett B, Wright B, Stetz J, Arquilla B. Randomized controlled trial of high fidelity patient simulators compared to actor patients in a pandemic influenza drill scenario. Resuscitation. 2010;81:872-6.

49. Brazzi L, Lissoni A, Panigada M, Bottino N, Patroniti N, Pappalardo F, et al. Simulation-based training of extracorporeal membrane oxygenation during H1N1 influenza pandemic: the Italian experience. Simul Healthc. 2012;7:32-4.

50. Einav S, Hick JL, Hanfling D, Erstad BL, Toner ES, Branson RD, et al. Surge capacity logistics: care of the critically ill and injured during pandemics and disasters: CHEST consensus statement. Chest. 2014;146:e17S-43S.

51. Al-Dorzi HM, Aldawood AS, Khan R, Baharoon S, Alchin JD, Matroud AA, et al. The critical care response to a hospital outbreak of Middle East respiratory syndrome coronavirus (MERS-CoV) infection: an observational study. Ann Intensive Care. 2016;6:101.

52. Chiu S, Black CL, Yue X, Greby SM, Scott Laney A, Campbell AP, et al. Working with influenza-like illness: presenteeism among US health care personnel during the 2014-2015 influenza season. Am J Infect Control. 2017: 1254-8. https://doi.org/10.1016/j.ajic.2017.04.008.

53. Mazer-Amirshahi M, Goyal M, Umar SA, Fox ER, Zocchi M, Hawley KL, et al. U.S. drug shortages for medications used in adult critical care (2001-2016). J Crit Care. 2017;41: 283-8.

54. Rebmann T, Greene LR, Hilley S, LaPointe S, Rosenbaum P, Russell B, et al. APIC position paper: extending the use and/or reusing respiratory protection in healthcare settings during disasters. Available: http://www.apic.org/Resource_/ TinyMceFileManager/Advocacy-PDFs/APIC_Position_Ext_the_Use_and_or_ Reus_Resp_Prot_in_Hlthcare_Settings1209l.pdf [Cited 10 Mar 2020].

55. CDC. Coronavirus Disease 2019 (COVID-19). In: Centers for Disease Control and Prevention. 11 Mar 2020. Available: https://www.cdc.gov/coronavirus/2 019-ncov/index.html [cited 12 Mar 2020].

56. Best BM, Capparelli EV, Diep H, Rossi SS, Farrell MJ, Williams E, et al. Pharmacokinetics of lopinavir/ritonavir crushed versus whole tablets in children. J Acquir Immune Defic Syndr. 2011;58:385-91.

57. Le AB, Hoboy S, Germain A, Miller H, Thompson R, Herstein JJ, et al. A pilot survey of the U.S. medical waste industry to determine training needs for safely handling highly infectious waste. Am J Infect Control. 2018;46:133-8.

58. Ong SWX, Tan YK, Chia PY, Lee TH, Ng OT, Wong MSY, et al. Air, surface environmental, and personal protective equipment contamination by severe acute respiratory syndrome coronavirus 2 (SARS-CoV-2) from a symptomatic patient. JAMA. 2020. https://doi.org/10.1001/jama.2020.3227.

59. Song F, Shi N, Shan F, Zhang Z, Shen J, Lu H, et al. Emerging 2019 Novel coronavirus (2019-nCoV) pneumonia. Radiology. 2020;295:210-217.

60. Chung M, Bernheim A, Mei X, Zhang N, Huang M, Zeng X, et al. CT imaging features of 2019 novel coronavirus (2019-nCoV). Radiology. 2020:295:202-207.

61. Guan W-J, Ni Z-Y, Hu Y, Liang W-H, Ou C-Q, He J-X, et al. Clinical characteristics of coronavirus disease 2019 in China. N Engl J Med. 2020. https://doi.org/10.1056/NEJMoa2002032.

62. Goh KJ, Choong MC, Cheong EH, Kalimuddin S, Duu Wen S, Phua GC, et al. Rapid progression to acute respiratory distress syndrome: review of current understanding of critical illness from COVID-19 infection. Ann Acad Med. 2020:49:108-118

63. Ruan Q, Yang K, Wang W, Jiang L, Song J. Clinical predictors of mortality due to COVID-19 based on an analysis of data of 150 patients from Wuhan, China. Intensive Care Med. 2020. https://doi.org/10.1007/s00134-020-05991-x.

64. World Health Organization. Clinical management of severe acute respiratory infection when novel coronavirus (2019-nCoV) infection is suspected. Interim guidance. 2020. Available: https://apps.who.int/iris/bitstream/ handle/10665/330893/WHO-nCoV-Clinical-2020.3-eng.pdf?sequence= 1 \&isAllowed=y . [Cited 12 Mar 2020].

65. Fan E, Del Sorbo L, Goligher EC, Hodgson CL, Munshi L, Walkey AJ, et al. An official American Thoracic Society/European Society of Intensive Care Medicine/Society of Critical Care Medicine clinical practice guideline: mechanical ventilation in adult patients with acute respiratory distress syndrome. Am J Respir Crit Care Med. 2017;195:1253-63.

66. Guérin C, Reignier J, Richard J-C, Beuret P, Gacouin A, Boulain T, et al. Prone positioning in severe acute respiratory distress syndrome. N Engl J Med. 2013;368:2159-68 
67. Acute Respiratory Distress Syndrome Network, Brower RG, Matthay MA, Morris A, Schoenfeld D, Thompson BT, et al. Ventilation with lower tidal volumes as compared with traditional tidal volumes for acute lung injury and the acute respiratory distress syndrome. N Engl J Med. 2000:342:1301-8.

68. National Heart, Lung, and Blood Institute Acute Respiratory Distress Syndrome (ARDS) Clinical Trials Network, Wiedemann HP, Wheeler AP, Bernard GR, Thompson BT, Hayden D, et al. Comparison of two fluid-management strategies in acute lung injury. N Engl J Med. 2006;354:2564-75.

69. Papazian L, Forel J-M, Gacouin A, Penot-Ragon C, Perrin G, Loundou A, et al. Neuromuscular blockers in early acute respiratory distress syndrome. N Engl J Med. 2010:363:1107-16.

70. Russell CD, Millar JE, Baillie JK. Clinical evidence does not support corticosteroid treatment for 2019-nCoV lung injury. Lancet. 2020;395:473-5.

71. Auyeung TW, Lee JSW, Lai WK, Choi CH, Lee HK, Lee JS, et al. The use of corticosteroid as treatment in SARS was associated with adverse outcomes: a retrospective cohort study. J Inf Secur. 2005;51:98-102.

72. Arabi YM, Mandourah Y, Al-Hameed F, Sindi AA, Almekhlafi GA, Hussein MA, et al. Corticosteroid therapy for critically ill patients with Middle East respiratory syndrome. Am J Respir Crit Care Med. 2018;197:757-67.

73. Wang $M$, Cao R, Zhang L, Yang $X$, Liu J, Xu M, et al. Remdesivir and chloroquine effectively inhibit the recently emerged novel coronavirus (2019-nCoV) in vitro. Cell Res. 2020:30:269-71.

74. Wax RS, Christian MD. Practical recommendations for critical care and anesthesiology teams caring for novel coronavirus (2019-nCoV) patients. Can J Anaesth. 2020. https://doi.org/10.1007/s12630-020-01591-X.

75. Da Zhuang K, Tan BS, Tan BH, Too CW, Tay KH. Old threat, new enemy: is your interventional radiology service ready for the coronavirus disease 2019? Cardiovasc Intervent Radiol. 2020. https://doi.org/10.1007/s00270-02002440-6.

76. Wong J, Goh QY, Tan Z, Lie SA, Tay YC, Ng SY, et al. Preparing for a COVID19 pandemic: a review of operating room outbreak response measures in a large tertiary hospital in Singapore. Can J Anesth. 2020. https://doi.org/10. 1007/s12630-020-01620-9.

77. Dichter JR, Kanter RK, Dries D, Luyckx V, Lim ML, Wilgis J, et al. System-level planning, coordination, and communication: care of the critically ill and injured during pandemics and disasters: CHEST consensus statement. Chest. 2014;146:e87S-e102S.

78. Marra A, Ely EW, Pandharipande PP, Patel MB. The ABCDEF bundle in critical care. Crit Care Clin. 2017:33:225-43.

79. Devereaux AV, Tosh PK, Hick JL, Hanfling D, Geiling J, Reed MJ, et al. Engagement and education: care of the critically ill and injured during pandemics and disasters: CHEST consensus statement. Chest. 2014;146: e1185-33s.

\section{Publisher's Note}

Springer Nature remains neutral with regard to jurisdictional claims in published maps and institutional affiliations. 